\title{
Caries experience in 7-, 12-, and 15-year-old schoolchildren in the canton of Basel-Landschaft, Switzerland, from 1992 to 2011
}

Waltimo, Tuomas ; Menghini, Giorgio ; Weber, Catherine ; Kulik, Eva M ; Schild, Samuel ; Meyer, Jürg

\begin{abstract}
OBJECTIVES To investigate the changes in caries experience and prevalence among schoolchildren of the canton of Basel-Landschaft, Switzerland, over the course of 20 years. METHODS A random sample of either schoolchildren aged 7, 12, and 15 years (in 1992) or aged 12 and 15 years (in 1997) or their respective school classes (2001, 2006 and 2011) was selected so that approximately $10 \%$ of schoolchildren could be examined. The children's $\mathrm{dmft}$ and DMFT scores were determined according to the WHO methodology and analyzed using cluster-adjusted ordinary multiple linear regression modeling. RESULTS For all age groups, the respective dmft/DMFT values decreased steadily from 1992 to 2006 but increased again in 2011. However, the observed differences were not statistically significant over the examination years from 2001 to 2011. Schoolchildren with a migrant background had approximately two- to threefold higher dmft/DMFT values. CONCLUSIONS In the years from 1992 to 2001, a steady decline in caries was observed in all age groups of schoolchildren examined in the canton of BaselLandschaft. However, in the subsequent 10 years, this decline has leveled off. The mean dmft/DMFT values are comparable to those in other parts of Switzerland. Migrants are a caries-risk group; the mean dmft/DMFT values were higher in schoolchildren with a migrant background than in the comparable Swiss children.
\end{abstract}

DOI: https://doi.org/10.1111/cdoe.12206

Posted at the Zurich Open Repository and Archive, University of Zurich

ZORA URL: https://doi.org/10.5167/uzh-121563

Journal Article

Accepted Version

Originally published at:

Waltimo, Tuomas; Menghini, Giorgio; Weber, Catherine; Kulik, Eva M; Schild, Samuel; Meyer, Jürg (2016). Caries experience in 7-, 12-, and 15-year-old schoolchildren in the canton of Basel-Landschaft, Switzerland, from 1992 to 2011. Community Dentistry and Oral Epidemiology, 44(3):201-208.

DOI: https://doi.org/10.1111/cdoe.12206 


\section{Caries experience in 7-, 12-, and 15-year-old schoolchildren in the canton of Basel-Landschaft, Switzerland, from 1992 to 2011}

Tuomas Waltimo ${ }^{1)}$, Giorgio Menghini ${ }^{2}$, Catherine Weber ${ }^{1)}$, Eva M. Kulik ${ }^{1)}$, Samuel Schild ${ }^{3)}$ and Jürg Meyer ${ }^{1)}$

1) Department for Preventive Dentistry and Oral Microbiology, School of Dental Medicine, University of Basel, Switzerland

2) Clinic for Preventive Dentistry, Periodontology and Cariology, Center for Dental Medicine, University of Zurich, Switzerland

3) Chief Dental Officer (retired), Department of Health and Economics, Canton of Basel-Landschaft, Liestal, Switzerland

Key words: epidemiology, caries experience, DMFT/dmft

Running head: Caries experience in schoolchildren in Switzerland

Corresponding author:

Dr. Eva Kulik

Department for Preventive Dentistry and Oral Microbiology, School of Dental Medicine, University of Basel, Hebelstrasse 3, CH- 4056 Basel, Switzerland Tel: 0041-61-2672597

Email: eva.kulik@unibas.ch 


\section{Abstract}

Objectives: To investigate the changes in caries experience and prevalence among schoolchildren of the canton of Basel-Landschaft, Switzerland, over the course of 20 years.

Methods: A random sample of either schoolchildren aged 7, 12 and 15 years (in 1992) or aged 12 and 15 years (in 1997) or their respective school classes (2001, 2006 and 2011) was selected so that approximately $10 \%$ of schoolchildren could be examined. The children's dmft and DMFT scores were determined according to the WHO methodology and analyzed using cluster-adjusted ordinary multiple linear regression modeling.

Results: For all age groups, the respective dmft/DMFT values decreased steadily from 1992 to 2006 but increased again in 2011. However, the observed differences were not statistically significant over the examination years from 2001 to 2011 . Schoolchildren with a migrant background had approximately two- to three-fold higher dmft/DMFT values.

Conclusions: In the years from 1992 to 2001 , a steady decline in caries was observed in all age groups of schoolchildren examined in the canton of BaselLandschaft. However, in the subsequent ten years, this decline leveled off. The mean dmft/DMFT values are comparable to those in other parts of Switzerland. Migrants are a caries risk group; the mean dmft/DMFT values were higher in schoolchildren with a migrant background than in the comparable Swiss children. 


\section{Introduction}

In the majority of the industrialized countries, a substantial overall decline in dental caries has been reported for children as well as for adults in recent $\operatorname{decades}^{1,2}$. However, this reduction in caries experience appears to be mostly based on declining rates in countries with a higher economic and social development, where various public health measures, e.g. the use of fluoridated dentifrices and toothpaste or community water and salt fluoridation, have been implemented to combat dental caries $^{1}$. There are contradictory reports about the dental caries rates in developing countries $^{1,3,4}$.

In Switzerland, caries prevention programs started in the 60 s. Since then, a reduction in caries has been documented for all age groups ${ }^{5-12}$. Many epidemiological studies have been carried out in schoolchildren since most children attend public schools in Switzerland and, therefore, are easily accessible resulting in high participation rates $(>70 \%)^{12}$.

However, in recent years this decline has leveled off and renewed increases in the prevalence of caries has been reported worldwide, in children as well as in adults ${ }^{13}$. In 4-year-old Swedish children, for example, the number of children with caries declined for 20 years but leveled off after $1987^{14}$. The oral health status of most Americans has improved between 1988-1994 and 1999-2004; however, this has not been the case for youths aged 2-5 years, where the prevalence of dental caries in the deciduous dentition has increased ${ }^{15}$. Similarly, an increase in caries in the deciduous dentition has been observed in Switzerland in the 1990s, which was thought to result mainly from the increasing proportion of schoolchildren with a migrant background ${ }^{7,8,16-18}$. 
Based on cantonal law, surveys on the dental health of schoolchildren have been performed in the canton of Basel-Landschaft, a region in Switzerland, every five years since 1992. The results of these dental examinations can reveal whether changes in oral health and dental caries occur over time. They should also provide the responsible authorities an overview of dental caries experience in schoolchildren and allow them to document the effectiveness of the prevention programs and evaluate the impact of interventions. This study presents the changes in caries in schoolchildren of the canton of Basel-Landschaft, Switzerland, over the course of 20 years. 


\section{Materials and Methods}

\section{Sampling of schoolchildren}

A simple random sampling of all the schoolchildren from the canton of BaselLandschaft, Switzerland, was performed for the first two examinations. In 1992, the 7-, 12- and 15-year-old schoolchildren were surveyed, and in 1997, the 12- and 15year-old schoolchildren were surveyed. As this procedure was not possible in the subsequent years due to data protection rights, a random sampling of the school classes (first, sixth and ninth grades) was performed (cluster sampling) in the years 2001, 2006 and 2011. The age-classes were defined as follows: 7-year-olds (range 6-8 years, first grade), 12-year-olds (range 11-13 years, sixth grade), and 15-yearolds (range 14-16 years, ninth grade).

Prior to the dental examination, the parents of the selected schoolchildren received information about the purpose and procedures of the examinations as well as a questionnaire to collect information on the date of birth, nationality, oral hygiene habits and attitude toward dental prophylaxis. Because of legal regulations, participation was mandatory.

\section{Dental examination}

The dental examinations in the years 1992 and 1997 were performed by the Clinic for Preventive Dentistry, Periodontology and Cariology, Center for Dental Medicine, University of Zurich, Switzerland. In the subsequent years, the examinations were conducted by the Department for Preventive Dentistry and Oral Microbiology, School of Dentistry, University of Basel, Switzerland. In 1997, the first-grade schoolchildren could not be examined for scheduling reasons. 
Dental examinations were generally conducted between February and July by two to four teams consisting of one dentist and one dental assistant each. Prior to the dental examination, specially trained oral health instructors talked to the schoolchildren about oral hygiene and the relation between dietary habits and oral health. Then, the schoolchildren brushed their teeth under the supervision of the instructors.

The dental examinations were performed in accordance with the methodology of the World Health Organization $(\mathrm{WHO})^{19,} 20$. All examinations were performed in schoolrooms under artificial light (halogen or high-performance LED headlamps). The teeth were dried with cotton pellets. To confirm the visual diagnosis of caries, a sickle probe (Maillefer Nr. 6, Maillefer, Ballaigues, Switzerland) was used in 1992 and 1997 and a CPI probe (CP-11,5B Parodontometer, Hu Friedy, Rotterdam, NL) was used in the later years. No bitewings or other X-ray examinations were made. To characterize the caries experience, the coding of the WHO was used, and the bases for the DMFT and dmft calculations were 28 and 20 teeth, respectively ${ }^{19,20}$.

\section{Reliability}

The examiners from the Clinic for Preventive Dentistry, Periodontology and Cariology in Zurich, who performed the clinical measurements in 1992 and 1997, had been calibrated multiple times because they performed analogous epidemiological studies on a routine basis ${ }^{9}$.

In 2001, the examiners from the Department for Preventive Dentistry and Oral Microbiology in Basel were calibrated against the head of the previous examinations analyzing children from two school classes (7- and 12-year olds). The intra-class correlation coefficients ${ }^{21}$ were 0.97 for the $\mathrm{dmft}$ and 0.90 for the DMFT. 
Before starting the studies in 2006 and 2011, the examiners from the Department for Preventive Dentistry and Oral Microbiology in Basel were mutually calibrated by comparing their dmft and DMFT findings in schoolchildren from two and three school classes (7- and 12-year olds), respectively, and the reliability of the clinical examinations between the pairs of examiners was assessed with kappa statistics, as recommended by the $\mathrm{WHO}^{20,22}$. The mean kappa values were 0.95 and 0.85 , respectively, for the years 2006 and 2011.

\section{Statistical analysis}

Data were collected using laptops. In 1992, 1997 and 2001, the data were analyzed using the HyperCard-based computer program WHO-Epident, a data entry and analysis program that was specifically developed at the Station for Oral Prevention (University of Zürich, Switzerland). In 2006 and 2011, a Microsoft Access-based data entry program developed at the University of Basel was used.

The DMFT and dmft values were calculated according to the WHO methodology ${ }^{19}$, 20. For 12- and 15-year-old schoolchildren, only the caries experience in the permanent dentition (DMFT) was calculated. The Significant Caries Index (SiC, average dmft or DMFT in the upper tertile, respectively $)^{23}$ was calculated for all age groups.

Data were coded in Excel (Microsoft Corporation, Redmond, WA, USA) and analyzed with STATA Version 10.1 (StataCorp LP, College Station, Texas, USA). Several distributional assumptions for each of the primary outcomes (DMFT, dmft, and $\mathrm{SiC}$ ), such as Poisson, zero inflated Poisson, negative binomial, zero inflated negative binomial and normal, were checked with Akaike and Schwarz information criteria (AIC, BIC). A negative binomial assumption was found to be the most appropriate. As the data were clustered by school-class, an appropriate approach 
was required. Both multiple negative binomial regression as well as ordinary multiple linear regressions with robust and school-class-adjusted estimates for the standard errors and p-values were separately computed for each age class (7-, 12- and 15year-olds). As the conclusions provided by both models (negative binomial and ordinary) were comparable, only the estimates provided by the school-class-adjusted ordinary multiple linear regression are reported here. Observed differences were considered to be statistically significant at $p<0.05$. For between-group comparisons $(2001,2006,2011)$ the Bonferroni-corrected significance level $p<0.016$ was used.

Chi-square $\left(\mathrm{X}^{2}\right)$ tests were used to evaluate the differences in caries prevalence during the years 2001-2011 for all age groups. Observed differences were considered to be statistically significant at $p<0.05$. 


\section{Results}

The present analysis is based on schoolchildren for whom both a dental examination was conducted and the date of birth and nationality were known.

Data were available for $74 \%$ to $100 \%$ of the examined children (Table 1). In general, participation was highest for the 7-year-old children, whereas the 15 -yearolds had the lowest participation rate. Objections by parents were rare. Absenteeism was more prominent in the higher grades and was mostly due to sickness on the day of examination or absence due to job training (for the 15-year-olds).

The caries experience of the 7-year-olds is shown in Table 2. In 2011, the mean dmft for 7 -years-olds was 1.91 , and $51 \%$ of the children had caries-free deciduous dentition. The caries experience in the deciduous dentition remained unchanged during the entire study period, and the differences noted between 2001 and 2011 were not statistically significant (cluster-adjusted regression analysis, $p>0.05$ ). Although the dmft value remained constant, a slight decrease of the d-component as well as a similar increase of the f-component was observed in 2011 compared to the previous examination.

With a value of approximately $50 \%$, the percentage of schoolchildren with a cariesfree deciduous dentition remained constant from 2001 to 2011 ( $x^{2}$ test, $p>0.05$ ).

After a decrease of $50 \%$ from 1992 to 2001 , the mean DMFT values and respective D-component remained constant in the subsequent years. In 2011, the 7year-old schoolchildren had a mean DMFT value of 0.15 and DT value of 0.07 . Eighty-nine percent had caries-free permanent dentition in 2011. In 2011, the mean DMFT for 12-year-olds was 0.85 , and $63 \%$ of the children were caries-free (Table 3). From 1992 to 2006, the DMFT values decreased steadily, but they increased again in 2011. However, over the examination years from 2001 to 
2011, the observed differences in the DMFT were not statistically significant (clusteradjusted regression analysis, $p>0.05$ ). From 2001 to 2011, the percentage of cariesfree schoolchildren was between $63 \%$ and $70 \%\left(x^{2}\right.$ test, $\left.p>0.05\right)$, and the mean number of untreated carious teeth (DT) was between 0.14 and 0.26 .

The mean DMFT for 15 -years-olds was 1.72 , and $43 \%$ of the children were cariesfree in 2011 (Table 3). The DMFT decreased steadily for the 15-year-olds from 1992 to 2006, but it increased again in 2011. As for the 12-year-olds, the observed differences were not statistically significant over the examination years from 2001 to 2011 (cluster-adjusted regression analysis, $p>0.05$ ). From 2001-2011, the percentage of caries-free schoolchildren was between $43 \%$ and $50 \%\left(x^{2}\right.$ test, $p>0.05)$ and the DT was between 0.27 and 0.31 .

Schoolchildren with a migrant background had approximately two- to three-fold higher rates of caries experience than Swiss schoolchildren (Table 4). These differences were statistically significant for all age groups during the study period from 2001 to 2011 (cluster-adjusted regression analysis, $p<0.001$ ). However, for schoolchildren with a migrant background, the dmft/DMFT values decreased over the examination period from 1992-2011.

The values for the $\mathrm{SiC}$ for the respective age group are shown in Table 5. For the deciduous dentition of 7-year-old schoolchildren, the $\mathrm{SiC}$ remained constant over the examination period, with a value of 5.18 in 2011 . For the 12- and 15-year-olds, the mean SiC values decreased from 1992 to 2006 but increased again in 2011 to 2.45 and 4.39 , respectively. 


\section{Discussion}

Our study provides an overview of the changes in caries experience among schoolchildren of the canton of Basel-Landschaft, Switzerland, over the course of 20 years. In the years from 1992 to 2001, a steady decline was observed in all age groups whereas in the subsequent ten years, this decline leveled off. The mean $\mathrm{dmft} / \mathrm{DMFT}$ values are comparable to those in other parts of Switzerland. Migrants appear to be a caries risk group as their mean dmft/DMFT values were higher in schoolchildren with a migrant background than in the comparable Swiss children.

A similar procedure was followed in all five studies to obtain comparable results. However, variations in the methodology could not be avoided because all clinical examinations were performed according to the respective published and recommended methodology of the $\mathrm{WHO}^{19,20}$. Therefore, a sickle probe was used in 1992 and 1997, whereas a CPI probe was used in the following years ${ }^{19,20}$. The use of a periodontal probe may lead to slightly lower $d / D$ values. Additionally, a simple random sample of schoolchildren could be selected in the years 1992 and 1997. Due to newly introduced data protection rights, this procedure was no longer possible in the subsequent years; therefore, a random sampling of the respective school classes was performed, and all schoolchildren in the selected classes were examined. Given the large sample sizes of the study groups, the impact of this change is likely to be small. Variations due to examiner bias are conceivable. However, the Basel examiners were not only calibrated against each other, they were also calibrated against their Zurich colleagues, who performed analogous epidemiological studies on a routine basis ${ }^{9}$, resulting in good reliability estimates.

Since the 1960s, epidemiological studies to assess caries in schoolchildren have been conducted in different parts of Switzerland. For all age groups, a marked 
decline in the mean dmft/DMFT values could be observed over time ${ }^{12,24}$. For 7 -yearolds, however, this decline has leveled off since the 1980s; since then, the mean dmft value has fluctuated around two, which is also the case for the schoolchildren from the canton of Basel-Landschaft examined in this study (Fig. 1). During the entire examination period, approximately half of the 7-year-olds had caries-free deciduous dentition, whereas approximately $10 \%$ of the schoolchildren in this age group had caries lesions in their permanent dentition. This age group is important for prophylactic measures because there is an association between the caries status in the primary dentition and in the corresponding young permanent dentition as well as between the caries experience in young permanent teeth with new caries increments in later life $25-27$.

For 12-year-olds (Fig. 2), a reduction in the mean DMFT of almost $50 \%$ was noted over the examination period, with the mean DMFT values of the canton of BaselLandschaft similar to those found in other parts of Switzerland. Over the entire examination period of 20 years, the mean DMFT for 12-year-olds of either Swiss or foreign nationality was never above three, which is the target value declared by the WHO for this age group ${ }^{28}$.

The causes for the decline in caries in Switzerland may be attributed to a number of factors $^{9,12,29}$. In 1955, Switzerland was the first country in the world to fluoridate salt, and by 2004 , over $80 \%$ of the population consumed fluoridated salt ${ }^{30}$. Additionally, fluoride-containing toothpastes were introduced in Switzerland in the 1960s, and today, these toothpastes account for more than $90 \%$ of the market ${ }^{29}$. Specially trained oral health instructors regularly instruct schoolchildren on oral hygiene and the relation between dietary habits and oral health. Swiss schoolchildren have very good oral hygiene habits according to an international comparison ${ }^{29}$. These good habits were also reported in our accompanying questionnaire regarding 
the oral hygiene habits and attitudes toward dental prophylaxis (data not shown). Changes in fluoride exposure or in the consumption of sugary drinks over the study period of 20 years are conceivable. Such changes might explain in part the observed levelling-off of the caries experience. However, such changes in habits are difficult to assess using a questionnaire which relies on self-assessment only.

In spite of the decline in caries observed in all age groups, the mean DMFT values were higher in schoolchildren of foreign nationality than in the respective Swiss children. An association between the caries experience and migrant background has already been reported in previous studies in Switzerland ${ }^{7,8,12,16-18}$.

These findings are in agreement with other studies that describe oral health inequalities arising from different socio-economic and social-cultural backgrounds, including migrant status ${ }^{13,31-35}$. In Denmark, where all children and adolescents can attend a free public dental service, there were major differences in dental health in all age groups when families with Danish and non-Danish backgrounds were compared. Notably, the mean caries experience among 5- and 7-year-old children with nonDanish mothers was three to four times higher than among children of Danish mothers, and a doubled rate was seen among adolescents ${ }^{31}$. Therefore, prevention programs should focus on the risk groups. To evaluate the effectiveness of such preventive care measures, different tools and methods to monitor changes in the caries risk over time have been described, including geo-mapping ${ }^{36}$.

In spite of the unchanged prevention measures of the cantonal and community school authorities, the steady decline in caries observed in all age groups of schoolchildren examined in the canton of Basel-Landschaft, leveled off in the years from 2001 to 2011 . Further examinations over the next years will show if this is only a transient situation or if additional efforts are required for further reductions. Health education efforts that focus primarily on migrants might be effective, as this group 
belongs to a caries risk group. 


\section{Acknowledgements}

These studies were commissioned and financed by the canton Basel-Landschaft. We would like to thank L. Strickler, the present Chief Dental Officer of the Canton of Basel-Landschaft, for providing authorization to perform the study in 2011.

We received toothbrushes and toothpaste from GABA (Switzerland) as presents for the schoolchildren, which is gratefully acknowledged.

We are very thankful to the dentists C. Brändle, T. Dobr, N. Kolesaric, M. Kurmann, M. Laaksonen, R. Weber and C. Vogel, who participated in the dental examinations. We would also like to thank S. Altenbach, C. Baumann, C. Frei, K. Hauck, I. Hauser-Gerspach, C. Salathé, I. Schweizer and D. Senapo for their help organizing and performing the field studies; the oral health instructors I. Jung and O. Maman for the optimal motivation and instruction of the schoolchildren during these studies; and M. Roos (Division of Biostatistics, Institute for Social and Preventive Medicine [ISPM], University of Zurich, Switzerland) for the statistical analysis.

Our special thanks go to all teachers for their support of and positive attitude toward these studies. 


\section{References}

1. Do LG. Distribution of caries in children: variations between and within populations. J Dent Res 2012;91: 536-43.

2. Marthaler TM. Changes in dental caries 1953-2003. Caries Res 2004;38: 17381.

3. Cleaton-Jones P, Fatti P, Bonecker M. Dental caries trends in 5- to 6-year-old and 11- to 13-year-old children in three UNICEF designated regions--Sub Saharan Africa, Middle East and North Africa, Latin America and Caribbean: 1970-2004. Int Dent J 2006;56: 294-300.

4. Cleaton-Jones P, Fatti P. Dental caries in children in South Africa and Swaziland: a systematic review 1919-2007. Int Dent J 2009;59: 363-8.

5. Altermatt-Tschopp E, Hefti A. [Caries prophylactic care in the Canton of Basel]. Schweiz Monatsschr Zahnmed 1985;95: 281-8.

6. Maurizio A, Dettling D, de Crousaz P, Menghini G. [Dental surveillance and prophylaxis among schoolchildren in the Canton of Geneva between 1980 and 1990]. Schweiz Monatsschr Zahnmed 1992;102: 407-10.

7. Menghini G, Steiner M, Marthaler TM. [The dental status of schoolchildren from abroad in Canton Zurich 1992 to 1994]. Schweiz Monatsschr Zahnmed 1995;105: 1529-33.

8. Steiner M, Menghini G, Curilovic Z, Marthaler T. [The caries occurrence in schoolchildren of the city of Zurich in 1970-1993. A view of prevention in new immigrants]. Schweiz Monatsschr Zahnmed 1994;104: 1210-8.

9. Steiner M, Menghini G, Marthaler TM, Imfeld T. Changes in dental caries in Zurich school-children over a period of 45 years. Schweiz Monatsschr Zahnmed 2010;120: 1084-104. 
10. Wegelin $\mathrm{H}$, Marthaler TM, Steiner M. [25 years of caries prevention in the canton of St. Gallen]. Schweiz Monatsschr Zahnmed 1988;98: 113-9.

11. de Crousaz P, Marthaler TM, Menghini GM, Steiner M. Fluoration du sel alimentaire en Suisse. Revue Européenne D'Odontologie, "Réalités Cliniques" 1993;4: 343-50.

12. Menghini G, Steiner M. Orale Gesundheit in der Schweiz - Stand 2006, Monitoring. Schweizerisches Gesundheitsobservatorium (OBSAN): Bundesamt für Statistik, 2007.

13. Bagramian RA, Garcia-Godoy F, Volpe AR. The global increase in dental caries. A pending public health crisis. Am J Dent 2009;22: 3-8.

14. Stecksen-Blicks C, Sunnegardh K, Borssen E. Caries experience and background factors in 4-year-old children: time trends 1967-2002. Caries Res 2004;38: 149-55.

15. Dye BA, Tan S, Smith V, Lewis BG, Barker LK, Thornton-Evans G, et al. Trends in oral health status: United States, 1988-1994 and 1999-2004. Vital Health Stat 11 2007: 1-92.

16. Menghini G, Steiner M, Leisebach T, Weber R. [Caries prevalence among 5year-olds in the city of Winterthur in the year 2001]. Schweiz Monatsschr Zahnmed 2003;113: 519-23.

17. Trummler A, Trummler $\mathrm{H}$. [The results of caries prophylaxis after 25 years of the School Dental Clinic in the city of St. Gallen]. Schweiz Monatsschr Zahnmed 1993;103: 156-61.

18. Guindy JS, Weber C, Meyer J. [Dental health of 7- and 12-year-olds in the canton of Solothurn (Switzerland)]. Acta Med Dent Helv 2000;5: 119-24.

19. WHO World Health Organization. Oral Health Surveys, Basic Methods. 3rd edition: World Health Organization, Geneva, 1987. 
20. WHO World Health Organization. Oral Health Surveys, Basic Methods. 4th edition: World Health Organization, Geneva, 1997.

21. Kingman A. Statistics in community oral health. In: Pine C, editor: Community Oral Health. Oxford: Wright, 1997: 147-62.

22. Hunt RJ. Percent agreement, Pearson's correlation, and kappa as measures of inter-examiner reliability. J Dent Res 1986;65: 128-30.

23. Bratthall D. Introducing the Significant Caries Index together with a proposal for a new global oral health goal for 12-year-olds. Int Dent J 2000;50: 378-84.

24. Bissig S, Peter L. Karies und Prävalenz von Schmelzopazitäten bei Schülern im Kanton Glarus 2012. Med. Diss. Zürich: Zürich; 2014.

25. Skeie MS, Raadal M, Strand GV, Espelid I. The relationship between caries in the primary dentition at 5 years of age and permanent dentition at 10 years of age - a longitudinal study. Int J Paediatr Dent 2006;16: 152-60.

26. Masood M, Yusof N, Hassan MI, Jaafar N. Assessment of dental caries predictors in 6-year-old school children - results from 5-year retrospective cohort study. BMC Public Health 2012;12: 989.

27. Tagliaferro EP, Ambrosano GM, Meneghim Mde C, Pereira AC. Risk indicators and risk predictors of dental caries in schoolchildren. J Appl Oral Sci 2008;16: 408-13.

28. World Health Organization. Oral Health Information Systems: Oral Health Surveillance [http://www.who.int/oral_health/action/information/surveillance/en/]. accessed: 2014/07/01.

29. Menghini G. Orale Gesundheit verschiedener Altersgruppen in der Schweiz. Zahnarzt Praxis 2009;6: 12-14. 
30. Marthaler TM. Overview of salt fluoridation in Switzerland since 1955, a short history. Schweiz Monatsschr Zahnmed 2005;115: 651-5.

31. Christensen LB, Twetman S, Sundby A. Oral health in children and adolescents with different socio-cultural and socio-economic backgrounds. Acta Odontol Scand 2010;68: 34-42.

32. Locker D. Deprivation and oral health: a review. Community Dent Oral Epidemiol 2000;28: 161-9.

33. Wendt LK, Hallonsten AL, Koch G. Oral health in pre-school children living in Sweden. Part III-A longitudinal study. Risk analyses based on caries prevalence at 3 years of age and immigrant status. Swed Dent J 1999;23: 1725.

34. Skeie MS, Espelid I, Skaare AB, Gimmestad A. Caries patterns in an urban preschool population in Norway. Eur J Paediatr Dent 2005;6: 16-22.

35. Ferro R, Besostri A, Meneghetti B, Olivieri A, Benacchio L, Tabaccanti S, et al. Oral health inequalities in preschool children in North-Eastern Italy as reflected by caries prevalence. Eur J Paediatr Dent 2007;8: 13-8.

36. Strömberg U, Holmn A, Magnusson K, Twetman S. Geo-mapping of time trends in childhood caries risk-a method for assessment of preventive care. BMC Oral Health 2012;12: 9. 
Table 1. Sample size and participation rate at the respective examinations for the schoolchildren who were 7,12 and 15 years old. Shown are the year of the examination, total number of schoolchildren in the canton of Basel-Landschaft in the respective grades, number of schoolchildren who were selected to participate, number of schoolchildren examined and respective participation rate.

\begin{tabular}{|c|c|c|c|c|c|}
\hline Year & Age (y) & $\begin{array}{l}\text { Total } \\
\text { schoolchildren in } \\
\text { the respective } \\
\text { grade }\end{array}$ & $\begin{array}{l}\text { Schoolchildren in the } \\
\text { respective age group } \\
\text { selected to participate }\end{array}$ & $\begin{array}{l}\text { Schoolchildren } \\
\text { in the study }\end{array}$ & Participation \\
\hline \multirow[t]{3}{*}{2011} & 7 & 2347 & 441 & 373 & $85 \%$ \\
\hline & 12 & 2788 & 498 & 415 & $83 \%$ \\
\hline & 15 & 2739 & 502 & 370 & $74 \%$ \\
\hline \multirow[t]{3}{*}{2006} & 7 & 2951 & 419 & 386 & $92 \%$ \\
\hline & 12 & 2785 & 425 & 347 & $82 \%$ \\
\hline & 15 & 2771 & 437 & 327 & $75 \%$ \\
\hline \multirow[t]{3}{*}{2001} & 7 & 2152 & 357 & 346 & $97 \%$ \\
\hline & 12 & 2929 & 532 & 532 & $100 \%$ \\
\hline & 15 & 2742 & 452 & 396 & $88 \%$ \\
\hline \multirow[t]{3}{*}{1997} & 7 & $\left.{ }^{*}\right)$ & & & \\
\hline & 12 & 3015 & 282 & 263 & $93 \%$ \\
\hline & 15 & 2707 & 300 & 263 & $88 \%$ \\
\hline \multirow[t]{3}{*}{1992} & 7 & 2677 & 260 & 250 & $96 \%$ \\
\hline & 12 & 2445 & 226 & 220 & $97 \%$ \\
\hline & 15 & 2145 & 273 & 252 & $92 \%$ \\
\hline
\end{tabular}

$\left.{ }^{*}\right)$ In 1997, the first-grade schoolchildren could not be examined for scheduling reasons. 
Table 2: Caries experience in the deciduous and permanent dentition of 7-year-old schoolchildren. Shown are the respective examination year, mean age (in years) and number of schoolchildren examined $(\mathrm{N})$, mean dmft/DMFT values, mean $\mathrm{dt} / \mathrm{DT}$ and percentage of caries-free participants $(\mathrm{dmft}=0$, resp. DMFT $=0)$.

\begin{tabular}{|c|c|c|c|c|c|c|c|c|}
\hline \multirow[b]{2}{*}{ Year } & \multirow[b]{2}{*}{ Age $(y)$} & \multirow[b]{2}{*}{$\mathrm{N}$} & \multicolumn{3}{|c|}{ Deciduous dentition } & \multicolumn{3}{|c|}{ Permanent dentition } \\
\hline & & & $\mathrm{dmft}$ & $\mathrm{dt}$ & Caries-free & DMFT & DT & Caries-free \\
\hline 2011 & 7.6 & 373 & 1.91 & 0.72 & $51 \%$ & 0.15 & 0.07 & $89 \%$ \\
\hline 2006 & 7.7 & 386 & 1.85 & 0.85 & $49 \%$ & 0.14 & 0.07 & $91 \%$ \\
\hline 2001 & 7.6 & 346 & 2.03 & 0.94 & $54 \%$ & 0.17 & 0.07 & $90 \%$ \\
\hline 1992 & 7.7 & 250 & 2.06 & 0.70 & $46 \%$ & 0.34 & 0.13 & $84 \%$ \\
\hline
\end{tabular}


Table 3: Caries experience in the permanent dentition of 12- and 15-year-old schoolchildren. Shown are the respective examination year, mean age (in years) and number of examined schoolchildren $(\mathrm{N})$, mean DMFT values, mean DT and percentage of caries-free participants (DMFT $=0)$.

\begin{tabular}{lllllll}
\hline & Year & Age $(\mathrm{y})$ & $\mathrm{N}$ & DMFT & DT & Caries-free \\
\hline 12-year-olds & 2011 & 12.8 & 415 & 0.85 & 0.18 & $63 \%$ \\
& 2006 & 12.8 & 347 & 0.61 & 0.14 & $70 \%$ \\
& 2001 & 12.7 & 532 & 0.84 & 0.26 & $67 \%$ \\
& 1997 & 12.8 & 263 & 1.05 & 0.14 & $56 \%$ \\
15-year-olds & 1992 & 13.1 & 220 & 1.62 & 0.22 & $44 \%$ \\
& 2011 & 15.8 & 370 & 1.72 & 0.29 & $43 \%$ \\
& 2006 & 15.8 & 327 & 1.49 & 0.31 & $50 \%$ \\
& 2001 & 15.8 & 396 & 1.59 & 0.27 & $49 \%$ \\
& 1997 & 15.9 & 263 & 3.03 & 0.42 & $33 \%$ \\
& 1992 & 15.9 & 252 & 3.25 & 0.32 & $29 \%$ \\
\hline
\end{tabular}


Table 4: Caries experience in the deciduous and permanent dentition by nationality. Shown are the respective examination year, nationality (Swiss or of foreign), mean age (in years), number of schoolchildren (N), mean DMFT/dmft-values and mean $\mathrm{dt} / \mathrm{DT}$.

\begin{tabular}{|c|c|c|c|c|c|c|c|c|}
\hline & \multirow[b]{2}{*}{ Year } & \multirow[b]{2}{*}{ Nationality*) } & \multirow[b]{2}{*}{$\mathrm{N}$} & \multirow[b]{2}{*}{ Age (y) } & \multicolumn{2}{|c|}{$\begin{array}{l}\text { Deciduous } \\
\text { dentition }\end{array}$} & \multicolumn{2}{|c|}{$\begin{array}{l}\text { Permanent } \\
\text { dentition }\end{array}$} \\
\hline & & & & & $\mathrm{dmft}$ & $\mathrm{dt}$ & DMFT & DT \\
\hline \multirow[t]{8}{*}{ 7-year-olds } & 2011 & $\mathrm{CH}$ & 285 & 7.6 & 1.55 & 0.58 & 0.13 & 0.05 \\
\hline & & Foreign & 88 & 7.6 & 3.07 & 1.17 & 0.23 & 0.13 \\
\hline & 2006 & $\mathrm{CH}$ & 288 & 7.7 & 1.41 & 0.54 & 0.12 & 0.05 \\
\hline & & Foreign & 97 & 7.7 & 3.19 & 1.77 & 0.21 & 0.14 \\
\hline & 2001 & $\mathrm{CH}$ & 245 & 7.1 & 1.62 & 0.54 & 0.08 & 0.03 \\
\hline & & Foreign & 88 & 7.1 & 3.31 & 2.13 & 0.42 & 0.17 \\
\hline & 1992 & $\mathrm{CH}$ & 203 & 7.2 & 1.64 & 0.48 & 0.25 & 0.10 \\
\hline & & Foreign & 35 & 7.3 & 3.71 & 1.51 & 0.80 & 0.31 \\
\hline \multirow[t]{10}{*}{ 12-year-olds } & 2011 & $\mathrm{CH}$ & 323 & 12.8 & - & - & 0.73 & 0.14 \\
\hline & & Foreign & 92 & 12.9 & - & - & 1.27 & 0.30 \\
\hline & 2006 & $\mathrm{CH}$ & 299 & 12.8 & - & - & 0.50 & 0.11 \\
\hline & & Foreign & 46 & 12.9 & - & - & 1.35 & 0.33 \\
\hline & 2001 & $\mathrm{CH}$ & 442 & 12.2 & - & - & 0.63 & 0.15 \\
\hline & & Foreign & 81 & 12.4 & - & - & 2.04 & 0.83 \\
\hline & 1997 & $\mathrm{CH}$ & 221 & 12.3 & - & - & 0.93 & 0.12 \\
\hline & & Foreign & 42 & 12.4 & - & - & 1.69 & 0.24 \\
\hline & 1992 & $\mathrm{CH}$ & 187 & 12.6 & - & - & 1.43 & 0.17 \\
\hline & & Foreign & 29 & 12.6 & - & - & 2.93 & 0.55 \\
\hline \multirow[t]{10}{*}{ 15-year-olds } & 2011 & $\mathrm{CH}$ & 304 & 15.8 & - & - & 1.55 & 0.24 \\
\hline & & Foreign & 66 & 15.9 & - & - & 2.50 & 0.53 \\
\hline & 2006 & $\mathrm{CH}$ & 281 & 15.8 & - & - & 1.38 & 0.28 \\
\hline & & Foreign & 45 & 15.8 & - & - & 2.02 & 0.42 \\
\hline & 2001 & $\mathrm{CH}$ & 345 & 15.3 & - & - & 1.41 & 0.21 \\
\hline & & Foreign & 42 & 15.3 & - & - & 3.07 & 0.55 \\
\hline & 1997 & $\mathrm{CH}$ & 207 & 15.5 & - & - & 2.59 & 0.32 \\
\hline & & Foreign & 56 & 15.3 & - & - & 4.66 & 0.77 \\
\hline & 1992 & $\mathrm{CH}$ & 210 & 15.4 & - & - & 3.10 & 0.23 \\
\hline & & Foreign & 36 & 15.2 & - & - & 3.83 & 0.86 \\
\hline
\end{tabular}

$\left.{ }^{*}\right)$ With the exception of the year 2011, it was not possible to obtain the nationality for all schoolchildren. Therefore, the numbers of Swiss and foreign children do not add up to the number of schoolchildren in Table 1. 
Table 5: Significant Caries Index ( $\mathrm{SiC}$ ) in the deciduous (mean $\mathrm{dmft}$ upper tertile) and permanent dentition (mean DMFT upper tertile).

\begin{tabular}{llrll}
\hline & year & \multicolumn{1}{c}{$\mathrm{N}$} & SiC Index dmft & SiC Index DMFT \\
\hline 7-year-olds & 2011 & 124 & 5.18 & - \\
& 2006 & 129 & 4.93 & - \\
& 2001 & 115 & 5.57 & - \\
12-year-olds & 1992 & 83 & 5.30 & - \\
& 2011 & 138 & - & 2.45 \\
& 2006 & 116 & - & 1.84 \\
& 2001 & 177 & - & 2.53 \\
15-year-olds & 1997 & 88 & - & 2.83 \\
& 1992 & 73 & - & 4.05 \\
& 2011 & 123 & - & 4.39 \\
& 2006 & 109 & - & 3.94 \\
& 2001 & 132 & - & 4.26 \\
& 1997 & 88 & - & 7.00 \\
& 1992 & 84 & - & 7.30 \\
\hline
\end{tabular}




\section{Figure captions}

Figure 1: Development of caries (mean dmft) in the deciduous dentition of 7-year-old schoolchildren from different Swiss cantons and cities over time.

$\rightarrow$ : Canton of Basel-Landschaft (this study);

$\rightarrow$ : Canton of Zurich ${ }^{9}$;

$\sim$ : City of Zurich ${ }^{12}$;

- : Canton of Glarus ${ }^{12,24}$

$=-$ : Canton of Ticino ${ }^{12}$

- : Canton of St. Gallen ${ }^{12}$.

Figure 2: Development of caries (mean DMFT) in the permanent dentition of 12year-old schoolchildren from different Swiss cantons and cities over time.

$\sim$ : Canton of Basel-Landschaft (this study);

$\rightarrow$ : Canton of Zurich ${ }^{9}$;

$\sim$ : City of Zurich ${ }^{12}$;

- : Canton of Glarus ${ }^{12,24}$;

$=-$ : Canton of Ticino ${ }^{12}$

$=$ : City of Wil ${ }^{12,24}$

: Canton of St. Gallen ${ }^{12}$;

$=$ : Cantons of Neuchatel and Fribourg ${ }^{11}$;

$=$ : Canton of Vaud ${ }^{11}$

$=$ : City of Yverdon ${ }^{11}$. 
Figure 1:

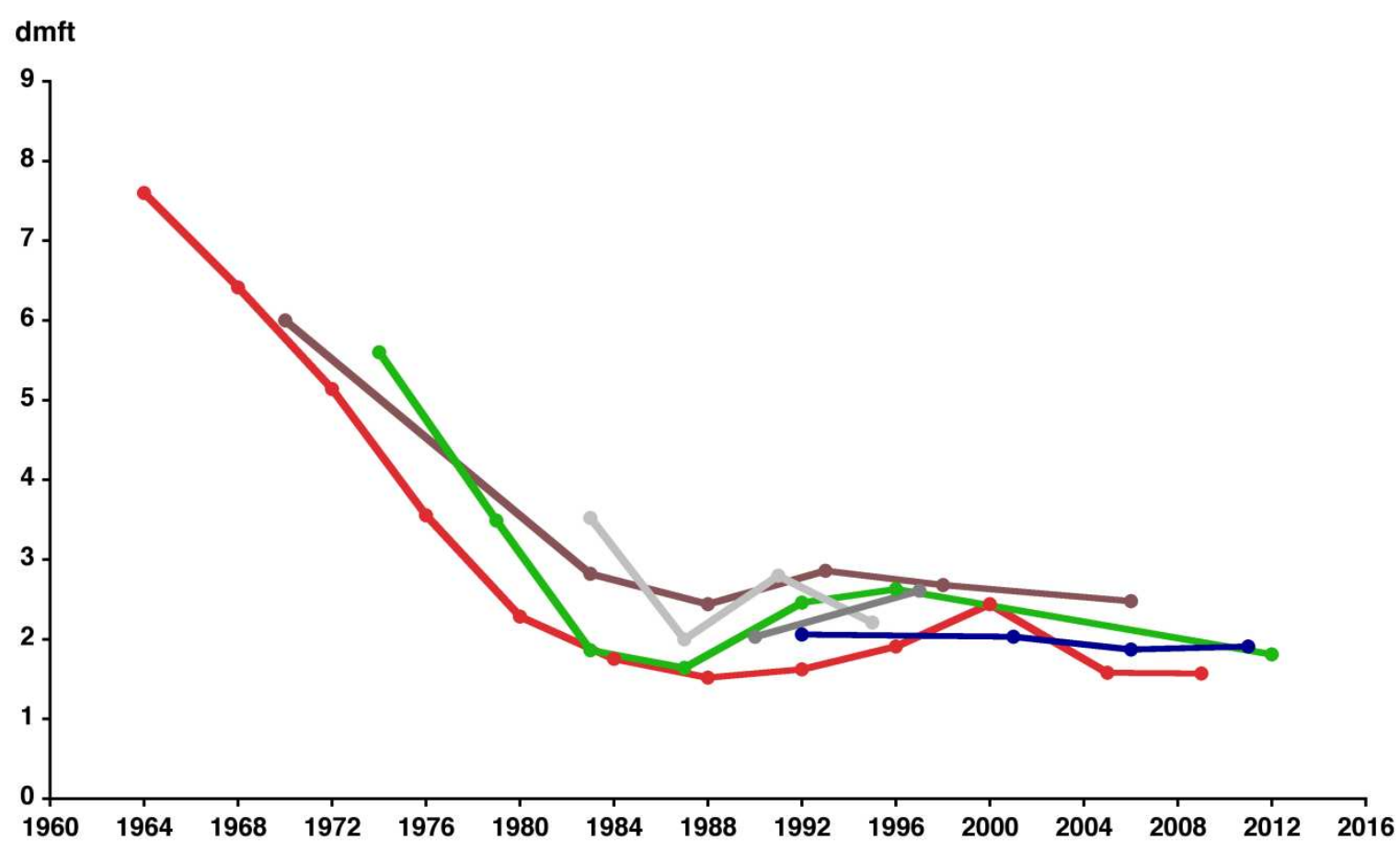


Figure 2:

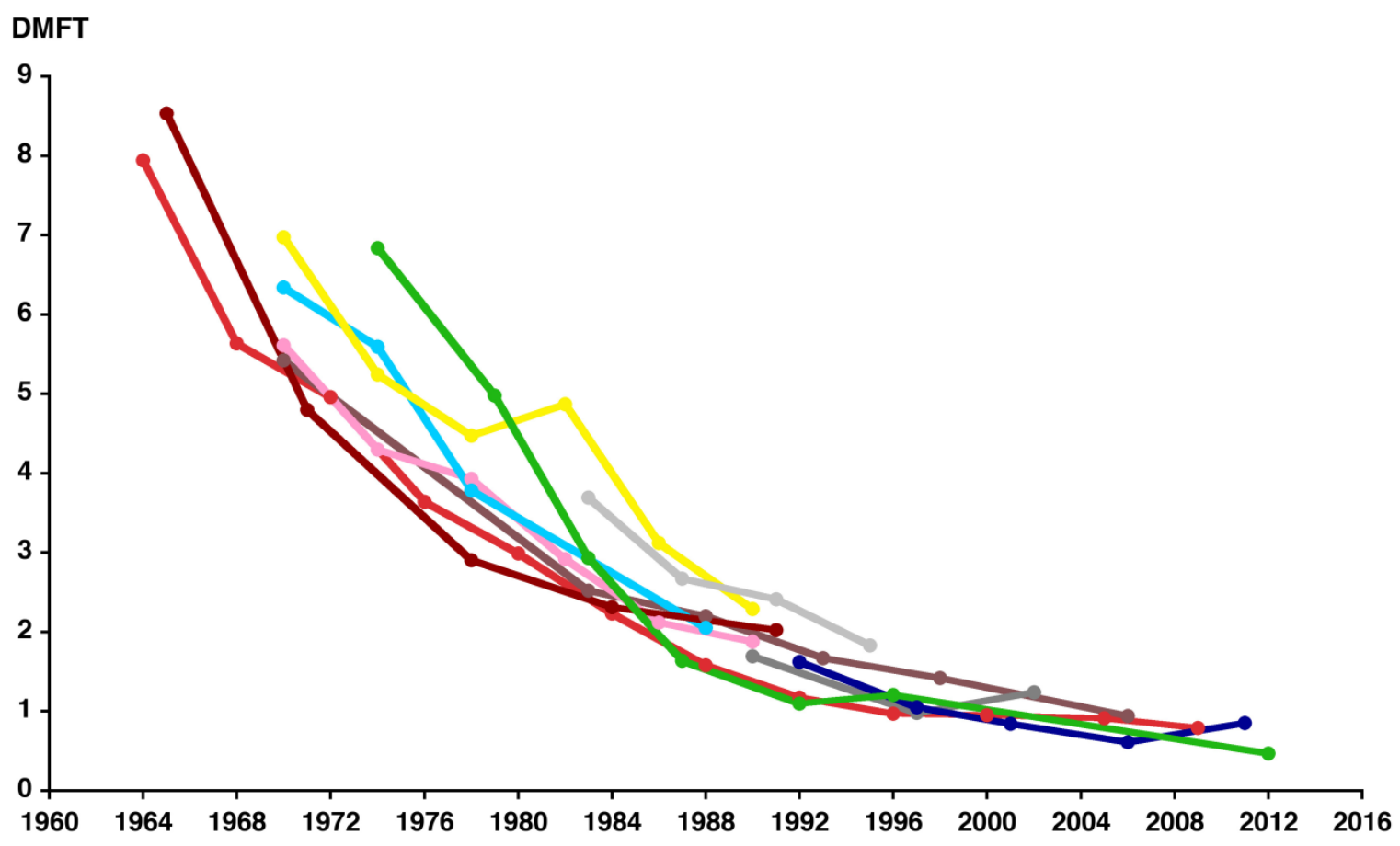

